DOI:

10.21789/issn.2422-2 704.1555

\title{
Historia del ordenamiento urbano de Valledupar*
}

\section{History of Urban Planning in Valledupar}

\author{
Jaime Bonet Morón \\ Director del Centro de Estudios Económicos Regionales (CEER), \\ Banco de la República. Cartagena, Colombia \\ jbonetmo@banrep.gov.co \\ Diana Carolina Ricciulli Marín \\ Investigadora del Centro de Estudios Económicos Regionales (CEER), \\ Banco de la República. Cartagena, Colombia \\ driccima@banrep.gov.co
}

\section{RESUMEN}

Los estudios de caso sobre desarrollo urbano en Colombia se han concentrado en dos de las ciudades más pobladas: Bogotá y Medellín (CastriIlón \& Cardona, 2014; Beuf, 2012). Mientras tanto, el éxito en la planificación de otras ciudades con menor población ha sido menos visible. El objetivo de este documento es reconstruir las diferentes etapas de la planificación urbana en Valledupar utilizando cartografía, archivos históricos, periódicos, entrevistas, documentos e imágenes. El periodo analizado corresponde a la segunda mitad del siglo XX. En su conjunto, la experiencia de Valledupar señala la importancia de formular y hacer cumplir los planes de desarrollo urbano. Igualmente, destaca el fortalecimiento institucional como un aspecto clave para el progreso local.

Una versión inicial de este documento fue publicada en Cuadernos de Historia Económica No. 51, disponible en http://repositorio.banrep.gov.co/bitstream/handle/20.500.12134/9735/CHE_51.pd$\mathrm{f}$ ? sequence $=8$ \&is Allowed $=\mathrm{y}$ 
Palabras clave: planificación urbana, desarrollo local, Colombia, Valledupar.

Códigos JEL: H70, N96, R58.

\section{ABSTRACT}

Most of the studies on urban development in Colombia have concentrated in two of the biggest cities: Bogotá and Medellín (Castrillón \& Cardona, 2014; Beuf, 2012). Meanwhile, the success of other smaller cities remains less visible. The aim of this paper is to reconstruct the different stages of urban planning in Valledupar using cartography, historical archives, newspapers, interviews, documents, and images. The period under study comprises the second half of the twentieth century. In the aggregate, the experience of Valledupar points out the importance of formulating and enforcing urban development plans. In addition, strengthening of institutions appear to be of outmost importance for local progress.

Keywords: Urban planning, local development, Colombia, Valledupar. JEL Codes: H70, N96, R58. 


\section{INTRODUCCIÓN}

Al igual que en el resto de Colombia, el crecimiento acelerado de la población en Valledupar se vivió con mayor intensidad en la segunda mitad del siglo XX. De acuerdo con los censos de población del Departamento Administrativo Nacional de Estadística (DANE), en el periodo intercensal 1912-1938, el crecimiento promedio anual de la población fue de 2,4 \%, mientras que en los tres periodos siguientes (1938-1951, 1951-1964 y 1964-1973) la tasa de crecimiento promedio anual de su población fue de $7,6 \%, 11,5 \%$ y $11,0 \%$, respectivamente. Valledupar tuvo la tasa de crecimiento más alta entre las capitales de la región Caribe, pasando de tener aproximadamente 16.000 habitantes en 1938 a cerca de 160.000 en 1973.

La llegada masiva de población a Valledupar resultó en cambios importantes en su estructura urbana, entendiendo esta última como las relaciones espaciales, económicas y sociales entre los distintos sectores que componen la ciudad (Levy, 2017). Por un lado, algunos grupos de inmigrantes constituyeron las primeras invasiones de terrenos en el sur de la ciudad, específicamente en lo que hoy son los barrios Primero de Mayo, Siete de Agosto, San Martín y Doce de Octubre (Cuello, 2015). Adicionalmente, el crecimiento poblacional y la aparición de nuevos asentamientos se dio sin un progreso similar en acceso a servicios públicos básicos. De acuerdo con el censo de población y vivienda de 1964, entre las capitales de la región Caribe, Valledupar era la segunda con menor acceso a servicios públicos después de Riohacha. El porcentaje de viviendas con disponibilidad de agua, sanitario, baño y luz en este año era de solo 32, 21, 25 y $25 \%$, respectivamente.

Este crecimiento desordenado, sin soluciones en materia de acceso a servicios públicos, llevó a la administración pública a tomar acciones frente a la planeación urbana del territorio. Los esfuerzos en esta dirección se vieron materializados en un primer plan de desarrollo urbano presentado por el Instituto Geográfico Agustín Codazzi (IGAC) en 1969 y en el primer plan maestro de acueducto y alcantarillado de 1975. Así mismo, el éxito en la formulación y ejecución de estos planes estuvo ligado al trabajo y la influencia de distintos actores e instituciones que se vieron involucrados en el proceso de planeación urbana de la ciudad.

Como resultado de la buena gestión y planeación, Valledupar logró coberturas de servicios públicos superiores a las de otras capitales de la región Caribe colombiana (Ochoa, 1998). De acuerdo con el censo de 
población y vivienda del DANE de 1993, Valledupar era la capital costeña con menor privación en acceso a servicios públicos básicos y la segunda con menor déficit cualitativo de vivienda después de Barranquilla. Además, la ciudad alcanzó un importante reconocimiento en Colombia y toda Latinoamérica. En 1998, el Banco Interamericano de Desarrollo (BID) destacó el caso de Valledupar como una experiencia exitosa en gestión del desarrollo urbano en América Latina (Rojas \& Daughters, 1998). Además, de acuerdo con Angell, Lowden y Thorp (2001), la capital cesarense fue considerada como una de las ciudades intermedias mejor planificadas de Colombia en el año 2000.

Este documento estudia la historia del desarrollo urbano de Valledupar durante la segunda mitad del siglo XX, permitiendo extraer lecciones importantes que resultan aplicables a otros contextos del país y la región. A través de cartografía histórica, documentos, imágenes, archivos históricos y prensa, se reconstruyen las etapas que guiaron el desarrollo urbano de esta ciudad y que la llevaron, en la década de 1990, a alcanzar un importante reconocimiento en el país y toda Latinoamérica. El trabajo se enriqueció igualmente con entrevistas realizadas a expertos que participaron activamente del proceso de ordenamiento urbano en la ciudad. ${ }^{1}$

En relación con la temática abordada, Fernández (2011) presenta un breve análisis desde la sociología del crecimiento urbano en Valledupar en el periodo 1950-2000. Por su parte, García (1999, s.f.) analiza algunos aspectos del desarrollo urbano de la ciudad en el siglo pasado. De manera similar, IDOM (2015) estudia el crecimiento de la huella urbana en la cabecera municipal a lo largo de la segunda mitad del siglo XX. Por su parte, Findeter (2017) y el Programa de Expansión Urbana de NYU (2016) analizan los patrones de expansión urbana y realizan propuestas concretas para lograr un crecimiento planificado y sostenible en los próximos años.

El documento está conformado por cuatro secciones. La historia del desarrollo urbano de esta ciudad se divide en dos grandes etapas que se abordan a través de la segunda y tercera sección. La primera estudia las bases para el ordenamiento del territorio que surgieron a mediados del siglo XX, mientras que la tercera presenta los planes de desarrollo crea-

\footnotetext{
Los autores agradecen la colaboración brindada por el alcalde Augusto Ramírez Uhía, los exalcaldes Rodolfo Campo Soto, Elías Ochoa Daza y María Clara Quintero, y por Heriberto Mendoza, Carlos García Aragón, Raúl Villegas Ochoa, Sonia Gómez Taboada, Carmen Mausa, Aurora Pachón, Eugenio Cortés, Magdalena Pradilla, Felipe Castro, Rosa Monsalve, Juan Manuel Ortiz, Jorge Maestre Jaraba, Blanca Zapata, Amparo Bello, Fernando Chalarca y Miguel Villazón Blay.
} 
dos en el marco de las leyes nacionales sobre ordenamiento territorial que guiaron el crecimiento de la ciudad por el resto del siglo. La cuarta sección presenta las reflexiones finales.

\section{BASES PARA EL ORDENAMIENTO URBANO}

A pesar de que el primer plan de desarrollo urbano para la ciudad de Valledupar data de 1969, sus orígenes se remontan a algunos años antes, cuando se llevaban a cabo acciones de mejora en la administración pública local. Inicialmente, a principios de la década de los sesenta, la Alcaldía Municipal trabajó en el fortalecimiento de la hacienda pública. Por una parte, por medio del acuerdo 27 del primero de octubre de 1963, se creó la Contraloría Municipal, con la cual se establecieron un conjunto de normas en materia de organización, administración, disposición, control y fiscalización de los ingresos municipales. Así mismo, se expidió el estatuto orgánico de hacienda y tesoro municipal, el cual contemplaba todo lo relacionado con el régimen presupuestario y la forma como se debía realizar su vigilancia y control (Dangond, 2002).

Por otro lado, y en línea con estas nuevas medidas, el acuerdo 7 de 1964 autorizó el cobro de una tarifa de predial equivalente al dos por mil con una sobretasa de $10 \%$ sobre el capital e intereses del mismo impuesto (Pachón, 1983). De acuerdo con Pachón (1983), como resultado de estos cambios, los predios dentro del perímetro urbano no edificado llegaron a pagar hasta una tarifa de ocho por mil.

En su conjunto, estas políticas contribuyeron a un aumento de la participación del recaudo de tributos en los ingresos totales del municipio. De acuerdo con el DANE, en 1969 los ingresos tributarios alcanzaron a representar más del $70 \%$ de los ingresos totales de Valledupar, por encima de la participación observada en las capitales con mayor población y actividad económica de la región: Cartagena (21\%), Barranquilla (39\%) y Santa Marta (43\%) (gráfica 1). En contraste, los ingresos no tributarios y las transferencias de Valledupar contaban con una participación de 21 y $5 \%$, respectivamente.

Paralelo al fortalecimiento de las instituciones fiscales y en relación directa con la planeación urbana, el acuerdo 32 de 1963 aprobó un plan de desarrollo integral para el municipio, el cual tendría un plazo máximo de 10 años a partir de 1964. Este incluía entre otras propuestas: la construcción de vías carreteables y caminos de penetración; la ejecución de un plan de 


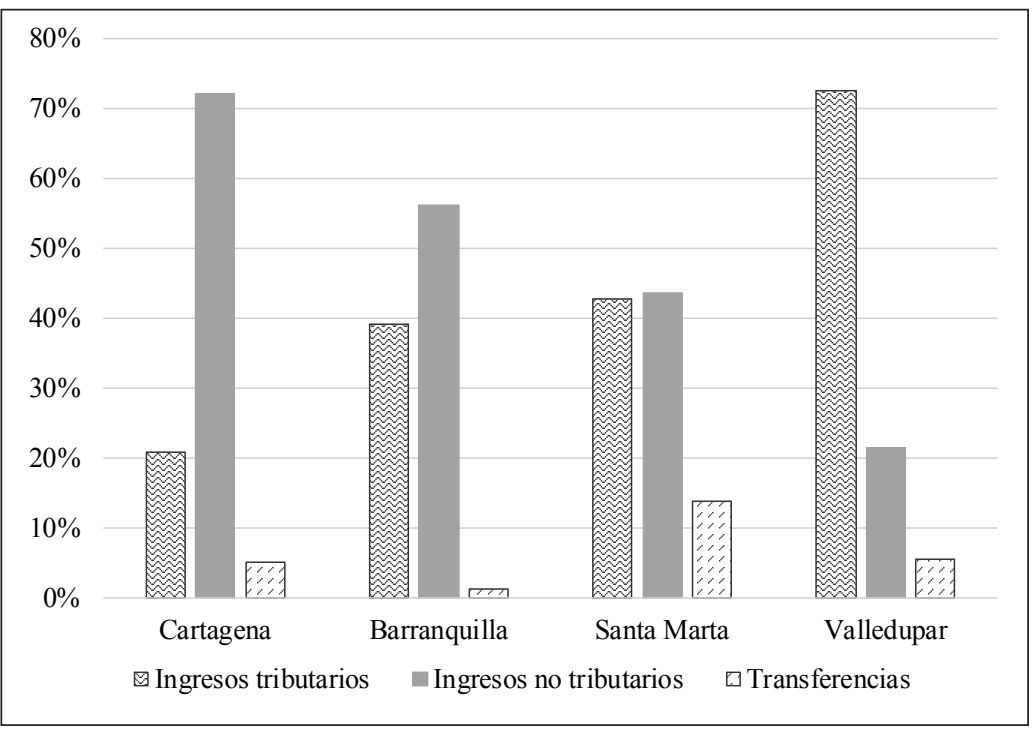

vivienda para obreros, campesinos y clase media; la construcción y ampliación de locales escolares, hospitales y centros de salud; la ampliación del acueducto y alcantarillado de la cabecera municipal; la electrificación urbana y rural; y el arreglo y pavimentación de calles (Dangond, 2002). Además de lo anterior, el plan de desarrollo de 1963 contempló la elaboración de un plano regulador de la cabecera municipal. Para este propósito, se contrataron los servicios del arquitecto cubano Manuel Carrerá, quien fue contactado por el señor Delio Cuello Gutiérrez, hermano de Manuel Germán Cuello (concejal en ese entonces) y amigo de Carrerá, quien era su vecino en el edificio García en Barranquilla (Bell, 2016).

Carrerá, nacido en 1909, había estudiado arquitectura en la Universidad de Columbia, Nueva York, y contaba con estudios de posgrado en planeación de la misma universidad. A mediados de la década de 1930, había llegado a Barranquilla contratado por la compañía constructora barranquillera Corneliessen y Salcedo para el desarrollo de algunos proyectos en esta ciudad. Años más tarde, entre 1945 y 1959, regresó a La Habana para desempeñarse como funcionario en el Ministerio de Obras de Cuba, en donde asumió los cargos de jefe de planeación y jefe encargado de hospitales (Bell, 2016).

En las labores que desempeñó, Carrerá se destacó por proponer soluciones a los principales problemas urbanos y arquitectónicos de la primera mitad del siglo XX. En relación con la arquitectura, se caracterizó por la simplificación formal y su estilo art deco, que quedó plasmado en diversas construcciones en las principales capitales de la región Caribe. Entre ellas
Gráfica 1.

Participación principales fuentes de ingreso (1969)

Fuente: series estadísticas de algunas variables socioeconómicas de 30 ciudades principales e intermedias 1965 1972 (DANE) y cálculos de los autores. 
se encuentran: el Teatro Cartagena, el Hotel Caribe y el edificio Ganem en Cartagena; el edificio García y el Teatro Murillo en Barranquilla; y el Hotel Tayrona en Santa Marta (hoy gobernación del Magdalena) (Bell, 2016).

En relación directa con la planificación, el arquitecto dejó su legado en el trazado urbano de Valledupar. De acuerdo con Cuello (2015), luego de haber sido contratado en 1963, el arquitecto llegó a la ciudad para conocer de cerca las necesidades de esta población; recorrió las tierras invadidas, se reunió con voceros de la administración pública y las comunidades, y expuso sus ideas sobre el trazado urbano más conveniente para la ciudad. En la proyección del futuro urbano de Valledupar, el arquitecto tomó como base sus principios rectores en materia de planificación, los cuales se remontaban a la reforma urbana de París del siglo XIX y a la influencia de su profesor en la Universidad de Columbia, Sir Raymond Unwin, precursor de la Ciudad Jardín (Bell, 2016).

Siguiendo sus principios rectores, Carrerá levantó planos y trazó las principales avenidas de Valledupar. De acuerdo con Cuello (2015, p. 24): “Carrerá trazó lo que hoy son las avenidas Simón Bolívar, Pastrana, la avenida que sale del terminal de transporte a encontrarse con la carretera que va a Valencia y demás poblaciones que bien conocemos, el tramo de la avenida Salguero hasta el terminal". Además, dialogó con los invasores para que estos colocaran sus viviendas en el sitio más adecuado para dejar calles amplias (Cuello, 2015). En general, toda la influencia de Carrerá quedó plasmada en el primer Plan Piloto de Desarrollo Urbano (PPDU) realizado por el IGAC en 1969, que, aunque no fue aprobado por el Concejo Municipal, fue aplicado parcialmente por la oficina de planeación (García, 1999; Pachón, 1983).

EI PPDU incluyó propuestas en distintas áreas enfocadas a guiar el crecimiento ordenado de la ciudad. En línea con el movimiento de Ciudad Jardín, en la mayoría de sus apartes se recomendó la arborización para lograr mejores condiciones de vivienda y trabajo. Además, el plan presentó una propuesta sobre la delimitación del perímetro urbano y sus áreas de expansión. Lo anterior, teniendo en cuenta las proyecciones en cobertura de servicios públicos básicos principalmente acueducto y alcantarillado (IGAC, 1969).

Con relación al diseño del plan vial, se propuso la arborización de la mayoría de las vías para solucionar la falta de protección solar. Además, para facilitar el flujo continuo de tráfico, propuso la construcción de glorietas en las intersecciones. Como parte de las propuestas, se presentó un plan vial exclusivo para el centro, determinando la ubicación de zonas verdes, 
parqueaderos y el ancho de los andenes para facilitar el flujo peatonal en esta zona de la ciudad (IGAC, 1969).

Finalmente, un último tema clave del PPDU fue una propuesta de zonificación que se encargó de determinar los mejores usos de la tierra y de separar usos incompatibles de la misma. En esta sección se presentó un esquema de sectorización que dividió el territorio con fines político-administrativos, identificando los núcleos urbanos que conformaban la ciudad y las distintas agrupaciones de barrios. Esto último sería de gran utilidad para la descentralización de ciertos servicios, así como para la concentración de otros de carácter comunitario (IGAC, 1969).

Un mapa realizado por el IGAC en 1970 presenta el trazado existente en la ciudad un año después de la formulación del PPDU (figura 1, panel A). Este último, permite identificar además los barrios que conformaban la huella urbana de la ciudad en ese entonces (figura 1, panel B). En particular, la ciudad contaba con 20 barrios. En el suroccidente ya estaban presentes algunos que eran resultado de las primeras invasiones (Primero de Mayo y San Martín), así como las importantes avenidas trazadas por Carrerá. También se podían apreciar algunas de las principales obras de infraestructura en la ciudad: al norte, el Club Valledupar; más al centro de la ciudad, la plaza Alfonso López, el cementerio central, el Instituto Técnico Pedro Castro Monsalvo (antes la Escuela de Artes y Oficios) y el Hospital Rosario Pumarejo de López; por su parte, hacia el sur, se podían apreciar la plaza de mercado, el estadio municipal, el Instituto de Fomento Algodonero, la Federación Nacional de Arroceros y la plaza de ferias y exposiciones.

\section{Insfopal y el primer plan maestro de acueducto y alcantarillado}

La optimización de la cobertura de servicios públicos se constituyó en otro de los cimientos claves para lograr el desarrollo urbano exitoso en la ciudad. Distintas propuestas en torno a este tema fueron abordadas por el plan de desarrollo integral de 1963, el PPDU del IGAC en 1969 y, más concretamente, por el plan maestro de acueducto y alcantarillado de 1975. No obstante, su ejecución estuvo determinada por la capacidad técnica de las instituciones encargadas de llevarlas a cabo (García, 1999).

El Instituto de Fomento Municipal (Insfopal), creado en 1950, fue una de estas instituciones. En particular, en 1957, el Insfopal quedó encargado de la construcción, operación y mantenimiento de los acueductos y alcantarillados de la ciudad. Así mismo, se le asignaron facultades para fijar tarifas 
de servicios públicos. En el desarrollo de estas nuevas funciones nacieron las Sociedades de Acueductos y Alcantarillados (ACUAS), conformadas con participación del departamento, los municipios y el Insfopal, con la finalidad de administrar y conservar las obras que este último realizara en las poblaciones afiliadas (Vélez, 2013).

Como resultado de esta reorganización, en 1961, el acueducto construido en Valledupar en 1942, que desde ese entonces era administrado por las Empresas Municipales de Servicios Públicos, pasó a manos de la Empresa de Acueducto y Alcantarillado del Magdalena Acuadelma (Empodupar, 1984). Una transformación que marcó el comienzo de una nueva etapa en la administración de los servicios públicos en la ciudad.

En primera instancia, Insfopal presentó en 1961 un proyecto completo para una planta de tratamiento de aguas potables para el acueducto de Valledupar. En ese entonces, el sistema de acueducto funcionaba con aguas procedentes del río Guatapurí. Estas llegaban a un tanque construido de ferroconcreto que servía como decantador primario, reteniendo las arenas y materiales pesados que arrastraban las aguas. Del tanque de decantación se derivaba una canalización que llevaba las aguas a un tanque de almacenamiento que al final distribuía las aguas sin ningún tipo de tratamiento (Insfopal, 1961).

El nuevo proyecto de 1961 incluyó una propuesta para el tratamiento completo de las aguas, la cual comprendía: (i) la decantación preliminar por simple gravedad aprovechando el desarenador ya construido; (ii) la aplicación de coagulantes a las aguas crudas; (iii) la floculación mecánica aprovechando equipos accionados por motores eléctricos en tanques especiales; (iv) la clarificación del agua floculada en tanques de sedimentación; y (v) la filtración del agua sedimentada. El presupuesto calculado para la ejecución total de esta obra, incluyendo tanques, filtros y tuberías, fue de 816.481 pesos, cifra equivalente al 73 \% de los ingresos totales de Valledupar en 1961 (Insfopal, 1961).

De acuerdo con García (1999), en 1962 y 1963, Acuadelma construyó las primeras estructuras de concreto para el tratamiento preliminar del agua. A su vez, y paralelo a estas obras, se construyeron nuevas redes de distribución que reforzaron las existentes y sirvieron para abastecer a algunos de los nuevos barrios producto de las invasiones a mediados de siglo como Primero de Mayo, 12 de Octubre y Simón Bolívar (García, 1999). 
Una segunda etapa en la administración de los servicios públicos inició luego de la creación del departamento del Cesar en 1967. En particular, en 1969, el acueducto y alcantarillado pasó a ser administrado directamente por Insfopal, entidad que estableció una dirección seccional en la nueva capital para administrar los servicios del nuevo departamento (Empodupar, 1984). Bajo esta nueva directriz, en 1970 tuvo lugar la culminación de la primera etapa de la planta de tratamiento. Además, en relación con el sistema de alcantarillado, se construyó el colector de aguas negras del barrio Novalito (García, 1999).
Figura 1.

Planos de Valledupar (1970)

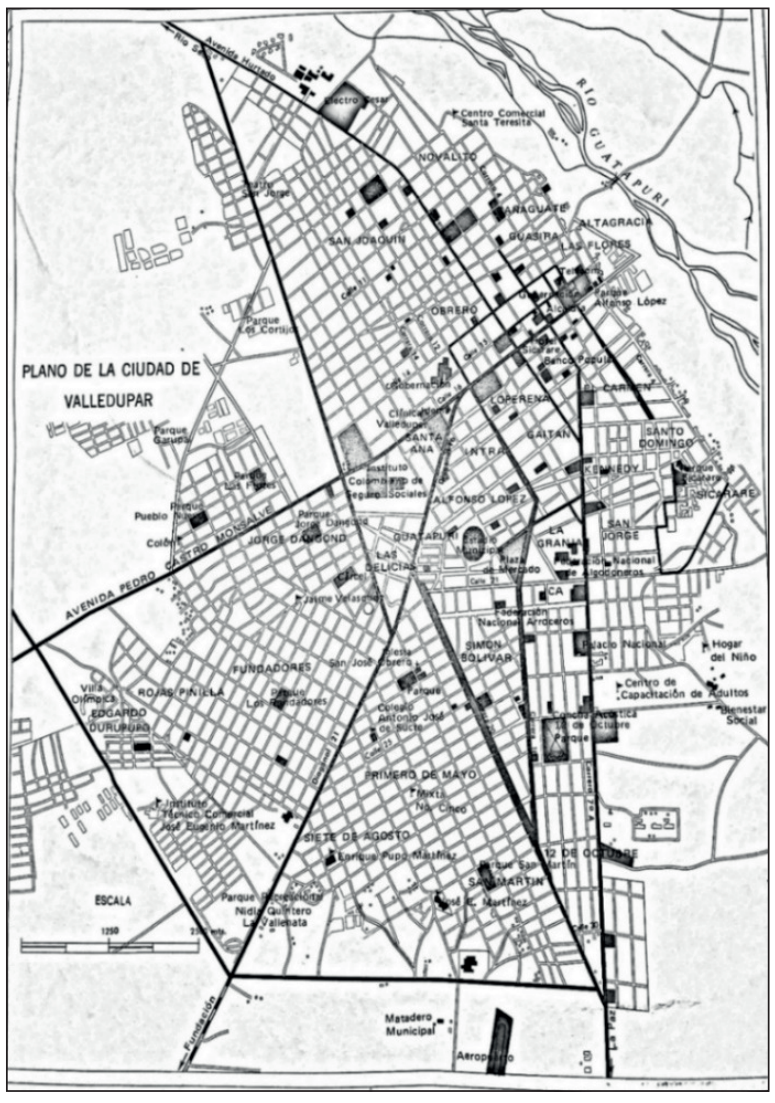

A. Plano del IGAC (1970)

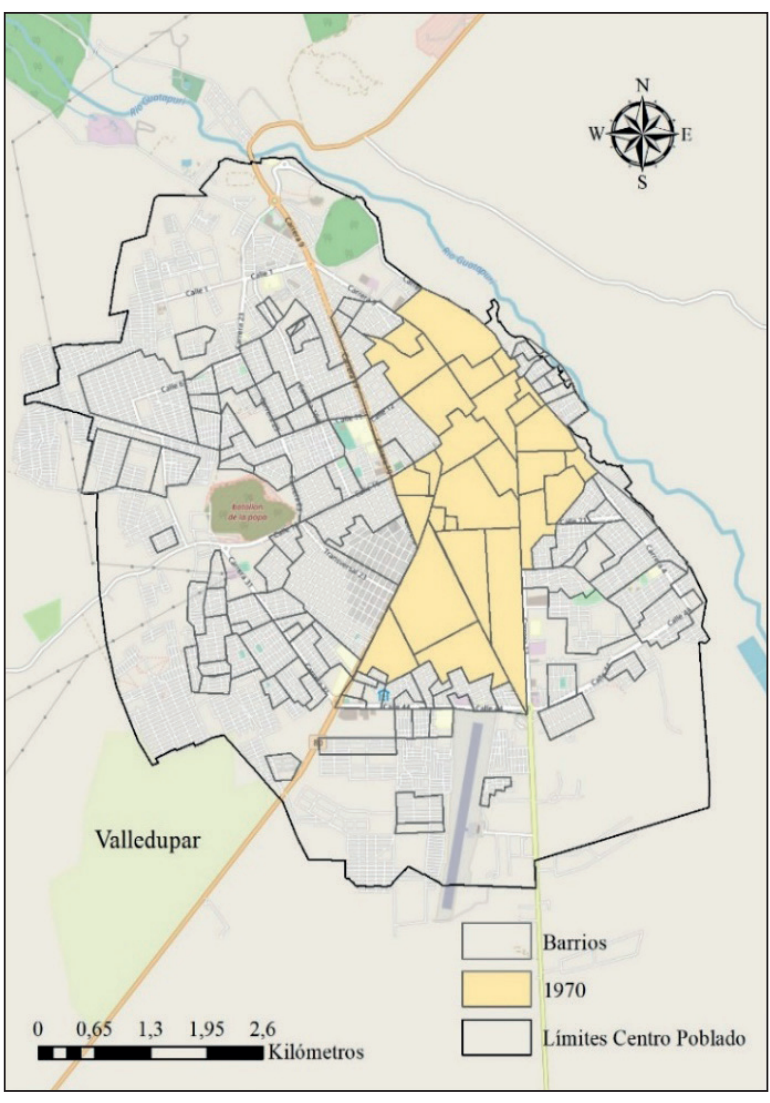

B. Crecimiento huella urbana por barrios

El conjunto de obras y cambios mencionados hasta el momento condujeron a un importante aumento en la cobertura de acueducto en la ciudad. Como se puede observar en la gráfica 2, entre 1964 y 1973, Valledupar presentó el mayor aumento en cobertura de este servicio dentro de las capitales de la región Caribe. De acuerdo con los censos de población del

Fuente: Cartografía histórica Instituto Geográfico Agustín Codazzi (IGAC) y elaboración de los autores a partir de información de la Secretaria de Planeación de Valledupar e IDOM (2015). DANE, la cobertura de este servicio pasó de $20 \%$ en 1964 a $73 \%$ en 1973, ubicándose en este último año como la cuarta ciudad con mayor cobertura 
TIEMPO \& ECONOMÍA

Vol. 7 N. ${ }^{\circ} 1$ | Enero - Junio del 2020 pp. $125-153$

con una cifra muy cercana a la de Cartagena (gráfica 2).

Los avances logrados en la década de los sesentas e inicios de los setentas continuaron en los años siguientes y fueron igualmente precedidos por cambios en la administración de los servicios. En 1974, se independizó la administración de los servicios de la ciudad, creándose la Empresa de Acueducto y Alcantarillado de Valledupar, Acuadupar (Empodupar, 1984). Por otra parte, en 1977, el vallenato Alfonso Araújo Cotes fue nombrado director general del Insfopal, cargo desde el cual impulsó el desarrollo de obras importantes para la capital del Cesar (García, 1999).

Gráfica 2. Cobertura de acueducto 1964 y 1973

Fuente: Censo Nacional de Población y Vivienda 1964 y 1973 DANE; cálculos de los autores. Nota: La cobertura de acueducto en 1964 es calculada con base en el número de viviendas con disponibilidad de agua dentro del hogar, la cual puede ser entendida como una cota superior de la cobertura de este servicio.

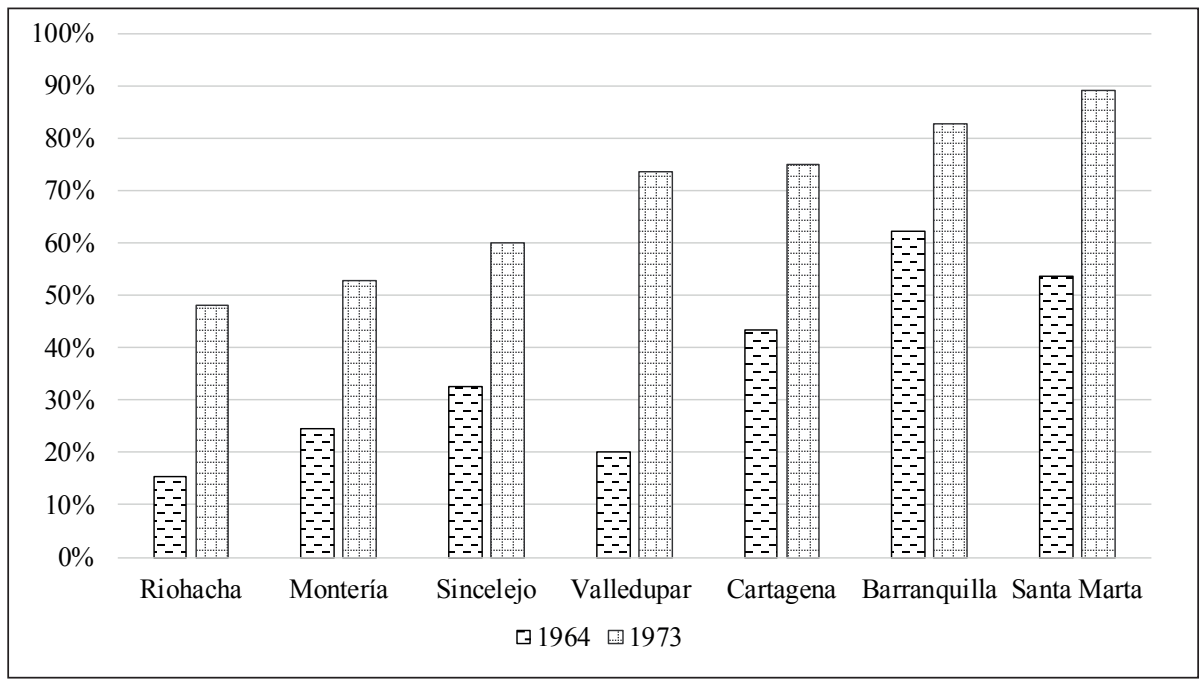

Bajo la nueva administración, en 1974, Acuadupar recibió un préstamo otorgado por el Banco Interamericano de Reconstrucción y Fomento (BIRF), por intermedio del Insfopal, por 31,2 millones de pesos (11.000 millones de pesos en precios constantes de 2019). Estos recursos fueron destinados a la financiación de obras para la optimización de la infraestructura de acueducto y alcantarillado y el diseño del primer plan maestro de acueducto y alcantarillado de la ciudad, propósito para el cual se contrataron los servicios de la firma Hidrotec Ltda. (García, 1999).

Algunas de las obras ejecutadas con los recursos del préstamo del BIRF incluyeron la optimización completa de la planta de tratamiento, la instalación de tuberías para la provisión del servicio en nuevos barrios, un análisis de alternativas para el tratamiento de aguas negras y el diseño de colectores principales y secundarios. Sobre el impacto de estas obras, Abel 
Darío Giovanetti, gerente de Acuadupar en 1975, comentó en entrevista con el periódico Antena del Cesar: "Mientras Valledupar contará dentro de diez años con servicios de acueducto con cubrimiento del $100 \%$, las perspectivas de construcción de alcantarillado son remotas, si se tiene en cuenta que el déficit de este servicio es del $70 \%$, y requiere inversiones en el orden de 150 millones de pesos".2

En los años que siguieron a estas obras continuaron los cambios en la administración de los servicios públicos. En 1977, dando cumplimiento a los decretos 2804 y 1157 de 1976, se reorganizó Insfopal y se crearon las Empresas de Obras Sanitarias (EMPOS), Acuadupar se transformó entonces en la Empresa de Obras sanitarias de Valledupar, Empodupar. Esta última, con potestad de manejar, además de los servicios de acueducto y alcantarillado, los de aseo público, mataderos, y plazas de mercado (García, 1999). En este caso, Empodupar se encargó de administrar tres servicios básicos para la ciudad: acueducto, alcantarillado y aseo público (Empodupar, 1984).

Con Empodupar, en los años ochenta se realizaron otro conjunto de obras, para lo cual se acudió igualmente a un préstamo del BIRF por intermedio del Insfopal. Algunas de estas incluyeron: la construcción de cuatro colectores de aguas residuales y dos emisarios finales, con sus respectivas redes secundarias e instalaciones domiciliarias, y la construcción de la laguna de estabilización para el tratamiento de aguas residuales antes de su vertimiento en el río Guatapurí (García, 1999).

Heriberto Mendoza, gerente de Empodupar durante el periodo 1979-1985, resalta la importancia que tuvo el cumplimiento de los planes maestros de acueducto y alcantarillado por aquellos años. De acuerdo con Mendoza, los diseños propuestos eran respetados por los dirigentes y el crecimiento urbano iba de la mano de la ampliación de la infraestructura de servicios públicos. Además, de acuerdo con la opinión del exgerente, existía un gran compromiso de los dirigentes locales con la ciudadanía, el cual se ha perdido en la actualidad; el último plan maestro ya no incluye diseño y además no es respetado a cabalidad. ${ }^{3}$

Periódico Antena del Cesar, 10 de marzo de 1975.

3 Entrevista con Heriberto Mendoza, Valledupar, 21 de junio de 2019. 
La buena gestión de la empresa durante la década de los ochenta fue destacada en un estudio sobre el estado de todas las Empos y Acuas en el país presentado por el Departamento Nacional de Planeación (DNP) en 1987. En este se resaltó a Empodupar como una de las entidades del sistema Insfopal con mayor eficiencia, mejor balance financiero y buenas perspectivas. La empresa fue clasificada como tipo A, mientras que otras como Empocesar y Empogira se ubicaron en tipo B, es decir, empresas en muy mala situación en cada una de las áreas evaluadas. Además, dentro de las empresas que operaban en la región Caribe, Empodupar fue la única que figuró dentro del primero grupo con mejor desempeño (El Diario Vallenato, 1987). ${ }^{4}$

En suma, la solidez de las instituciones locales durante esta primera etapa facilitó el desarrollo urbano de la ciudad, el cual comenzó a ser guiado por los primeros planes: el PPDU y el plan maestro de acueducto y alcantariIlado. Por su parte, el fortalecimiento de las instituciones fiscales, así como la solidez financiera y la capacidad de ejecución de Empodupar, permitieron la realización de obras importantes para la optimización de la infraestructura de servicios públicos básicos.

\section{VALLEDUPAR EN EL MARCO DE LAS LEYES NACIONALES SOBRE ORDENAMIENTO TERRITORIAL}

Las directrices del arquitecto Manuel Carrerá, el primer plan de desarrollo urbano y el plan maestro de acueducto y alcantarillado fueron el inicio de una larga tradición en planificación de la ciudad. AI PPDU del IGAC le siguieron en su orden: el Plan Integral de Desarrollo Urbano de Valledupar (PIDUV) de 1983, el Plan de Desarrollo de Valledupar Siglo XXI (PDVS) de 1990 y el Plan de Ordenamiento Territorial (POT) de 1999. Los tres formulados en el marco de leyes nacionales que exigían su elaboración. En particular, y a pesar de que únicamente la Ley de Desarrollo Territorial (1997) incluyó directrices específicas con relación al ordenamiento del territorio, Valledupar abordó estos temas desde su primer plan (Alcaldía de Valledupar, 1999). Los apartados a continuación presentan los planes que siguieron al PPDU, así como los actores e instituciones que jugaron un papel clave en su ejecución.

\section{Ley Orgánica de Desarrollo Urbano y PIDUV 1982-1983}

El artículo tercero de la Ley Orgánica de Desarrollo Urbano de 1978 estableció que todo núcleo urbano con más de 20.000 habitantes debía

4 El Diario Vallenato, 7 de septiembre de 1987. 
formular su respectivo plan integral de desarrollo. Siguiendo esta reglamentación, el acuerdo 3 de mayo 7 de 1981 autorizó a la Alcaldía de Valledupar a contratar un empréstito con el Fondo Nacional de Proyectos de Desarrollo (Fonade) para financiar la realización de este estudio para la ciudad (Alcaldía de Valledupar, 1999). En entrevista realizada el 4 de diciembre de 2018, la doctora María Clara Quintero (alcaldesa de Valledupar 1981-1982) manifestó que al llegar a la alcaldía se enfrentó a la necesidad de gestionar recursos ante el gobierno nacional, en donde le exigieron que se necesitaba de un plan integral aprobado para poder tener acceso a los fondos. Su elaboración inició en 1982, bajo la dirección de la arquitecta Aurora Pachón, y en 1983 este fue aprobado por el Concejo Municipal, durante la administración municipal de Alfredo Cuello Dávila. De acuerdo con María Clara Quintero, Valledupar fue la tercera ciudad intermedia en Colombia en contar con un plan de desarrollo integral, que en este caso fue más conocido como el PIDUV. ${ }^{5}$

Uno de los temas abordados por el PIDUV fue el desarrollo físico de la ciudad. A principios de la década de 1980 se observaba un crecimiento urbano en dirección sur y suroccidente. La figura 2 presenta un mapa realizado por el IGAC en 1984 y el crecimiento de la huella urbana entre 1970 y 1984. En efecto, el mayor desarrollo se observa en la dirección suroccidente; los barrios Jorge Dangond, Fundadores, Rojas Pinilla y Edgardo Pupo fueron algunos de los nuevos asentamientos que aparecieron en la cartografía de 1984 (figura 2). Se observa también la consolidación de algunos barrios en el norte de la ciudad, como el Novalito, el Conjunto Residencial del Norte y los Campanos. Así mismo, se empieza a llenar el vacío existente entre el barrio Primero de Mayo y el Aeropuerto, con algunos barrios como la Rueda, la Felicidad y el Prado (IDOM, 2015).

En línea con estos nuevos desarrollos, el PIDUV propuso que el crecimiento se siguiera dando en esta dirección: sur y suroccidental. Primero, teniendo en cuenta que el río Guatapurí en el lado noroccidental constituía una barrera natural que contenía el desarrollo en la dirección opuesta. Por otro lado, los costos en infraestructura y vialidad que implicaba el desarrollo hacia el río serían muy altos e injustificados, teniendo en cuenta que existía una alternativa de expansión. Con base en estas consideraciones, el plan determinó las áreas más convenientes para el futuro crecimiento y desarrollo de Valledupar, fijando un perímetro acorde con la cobertura de servicios públicos básicos y la infraestructura vial presente en la época (Pachón, 1983).

5 Entrevista con María Clara Quintero, Valledupar, 4 de diciembre de 2018. 
TIEMPO \& ECONOMÍA

Vol. 7 N. ${ }^{\circ} 1$ | Enero - Junio del 2020

pp. $125-153$

La cobertura de servicios públicos básicos fue otro de los temas abordados por el PIDUV. En este caso, se recomendó a Empodupar iniciar un plan de recuperación de fugas de agua con el objeto de reducirlas de 40 a 25\%, una cifra que se consideraba aceptable en el medio. Además, se propuso actualizar el estudio del plan maestro de acueducto y alcantarillado de 1975

Figura 2. con el objeto de incluir las nuevas áreas de expansión de la ciudad y estudiar Planos de Valledupar 1984 posibles ampliaciones de la infraestructura (Pachón, 1983).

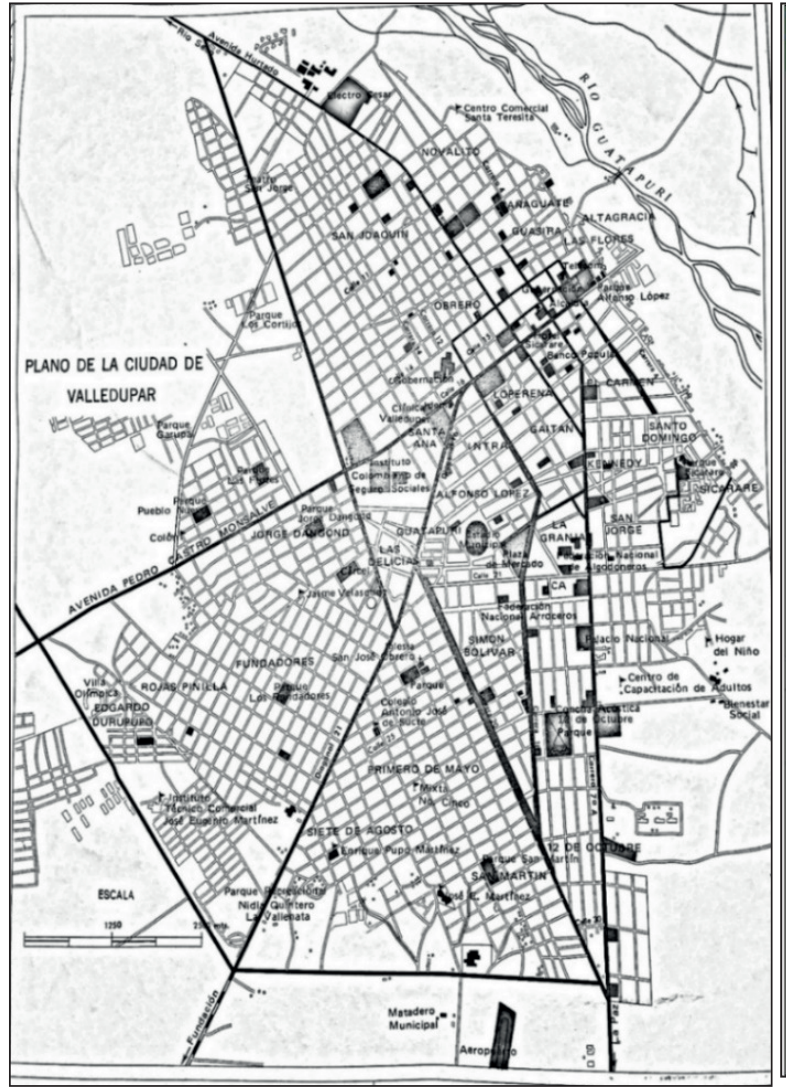

Fuente: Cartografía histórica Instituto Geográfico Agustín Codazzi (IGAC) y elaboración de los autores a partir de información de la secretaria de planeación de Valledupar y IDOM

(2015)
A. Plano IGAC (1984)

B. Crecimiento huella urbana por barrios (1984)

En relación específica con el tema de saneamiento básico, una de las principales recomendaciones del PIDUV fue el diseño del alcantarillado de aguas y lluvias de la ciudad (Pachón, 1983). Sobre este proyecto, en los primeros años posteriores a la formulación del plan, algunos líderes políticos consideraban que esta obra no era prioritaria para el desarrollo de la ciudad. ${ }^{6}$ Sin embargo, la Sociedad de Ingenieros del Cesar, incluyendo a la arquitecta Aurora Pachón, defendieron esta propuesta hasta convertirla en 
realidad. ${ }^{7}$ De esta manera, en septiembre de 1987 fue adjudicada la primera fase de esta obra por un valor de 31 millones de pesos (El Diario Vallenato, 1987). ${ }^{8}$ Dos años más tarde, en septiembre de 1989, la prensa local reportaba que el alcantarillado pluvial se encontraba funcionando en un $60 \%$ (El Diario Vallenato, 1989). ${ }^{9}$

La obra del alcantarillado pluvial y, en general, todas las propuestas contempladas en el PIDUV, conformaron parte del legado que dejó la arquitecta Aurora Pachón en el ordenamiento de Valledupar. Su labor como asesora de la oficina de planeación se prolongó a lo largo de 20 años, permitiendo una continuidad en las políticas de planeación y desarrollo urbano. En una entrevista, la doctora Pachón manifestó que trabajó durante ese periodo con distintas administraciones de diferentes partidos políticos, manteniendo siempre una discusión técnica sobre los distintos temas. Su vinculación a Valledupar se dio a raíz de un concurso de méritos que vio en un periódico al cual se presentó y fue seleccionada. Pachón recuerda que en Valledupar siempre se dio una discusión técnica con mucha participación de la ciudadanía y de asociaciones de profesionales, como la Sociedad de Arquitectos de Colombia (SAC). ${ }^{10}$

\section{Descentralización y Plan de Desarrollo de Valledupar en el siglo $X X I$}

A finales de los ochenta y principios de los noventa, Colombia inició un proceso de descentralización política y económica que se vivió con mayor intensidad con la Constitución Política de 1991. Por una parte, por medio del Acto Legislativo 01 de 1986, se reglamentó la elección popular de alcaldes en el país. Adicionalmente, y en relación con las responsabilidades de gasto de las entidades territoriales, la Constitución Política de 1991 otorgó mayores competencias a municipios y departamentos, aumentando a su vez los recursos que estos recibían por concepto de transferencias (Bonet, Pérez, \& Ricciulli, 2018).

La descentralización en ingresos y gastos resultó en un importante crecimiento de las transferencias nacionales que recibía Valledupar. De acuerdo con las ejecuciones presupuestales del DNP, durante el periodo 1990-1995 el crecimiento real anual de las transferencias en la ciudad fue de 22,8 \% (gráfica 3). Además, y a pesar del crecimiento en esta fuente de recursos,

El Diario Vallenato, 6 de agosto de 1987.

8 El Diario Vallenato, 25 de septiembre de 1987.

9 El Diario Vallenato, 18 de septiembre de 1989.

10 Entrevista telefónica realizada el 24 de enero de 2019. 
Valledupar aumentó en estos años su recaudo de ingresos propios. En el mismo periodo, los ingresos tributarios y no tributarios lograron un crecimiento real anual superior al de las transferencias: 24,8 y $57,6 \%$, respectivamente. De hecho, en 1990, Valledupar contaba con la mayor participación de predial e ingresos no tributarios entre de las principales capitales de la región: 18 y 19\% de los ingresos totales, respectivamente (gráfica 4).

El fortalecimiento de la gestión pública reflejado en las cuentas fiscales fue resultado de acciones complementarias en distintos frentes. Al respecto, Rodolfo Campo Soto, alcalde de Valledupar en los periodos 1988-1990 y 1992-1994, resalta cuatro pilares que guiaron las administraciones de la época: "pulcritud, honestidad, trabajo y apostolado; participación comunitaria; planificación como norma de gobierno; y mejoría de la hacienda pública"."1

En primera instancia, y en relación con el fortalecimiento de la hacienda pública, la alcaldía, con el apoyo técnico de la Dirección de Apoyo Fiscal (DAF) del Ministerio de Hacienda y Crédito Público, formuló un código de impuestos municipales y creó un estatuto orgánico de presupuesto. A su vez, y en línea con estas medidas, aumentó la tarifa del predial y adoptó instrumentos como el cobro de una sobretasa a la gasolina de 6 \% (Maldonado, 2004). Según Ochoa (1998), la puesta en marcha de estas y otras medidas no solo permitió a la administración pública aumentar sus ingresos propios, sino también contar con una mayor independencia en el gasto de sus recursos.

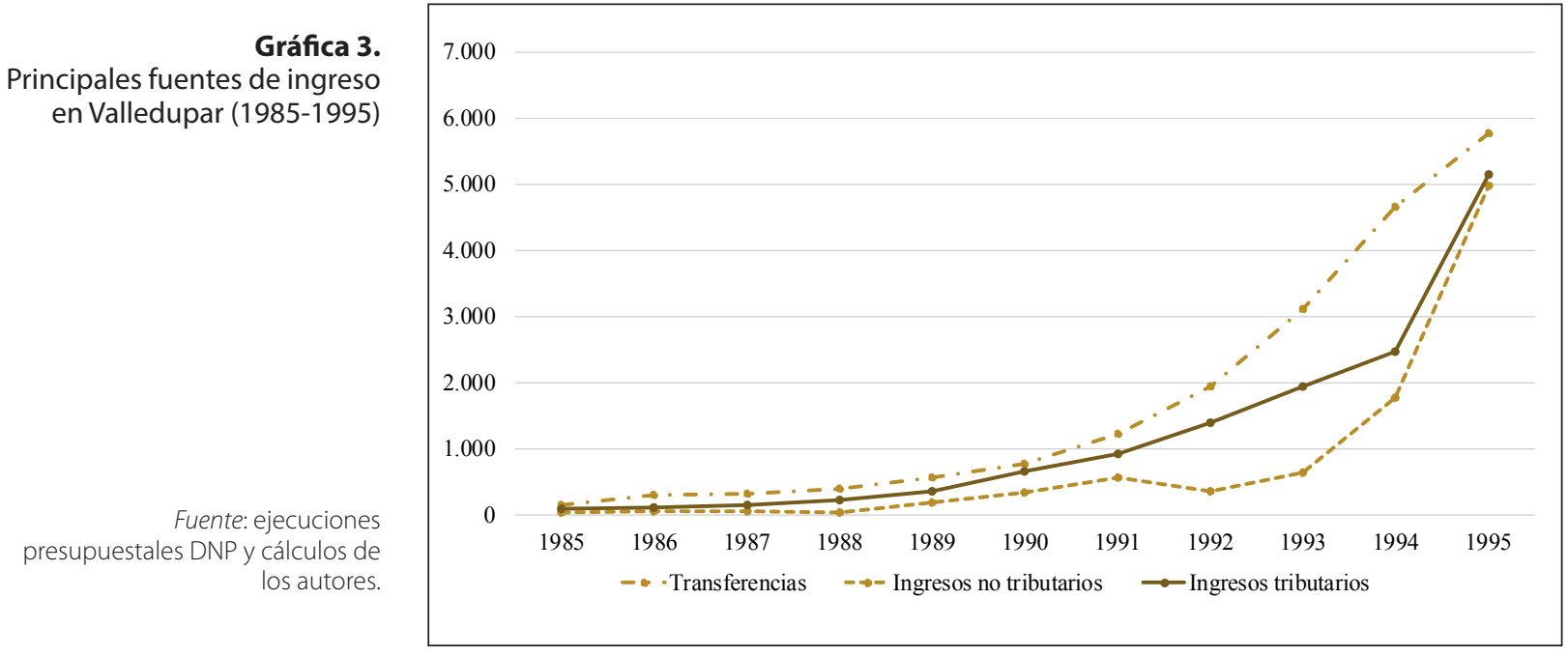




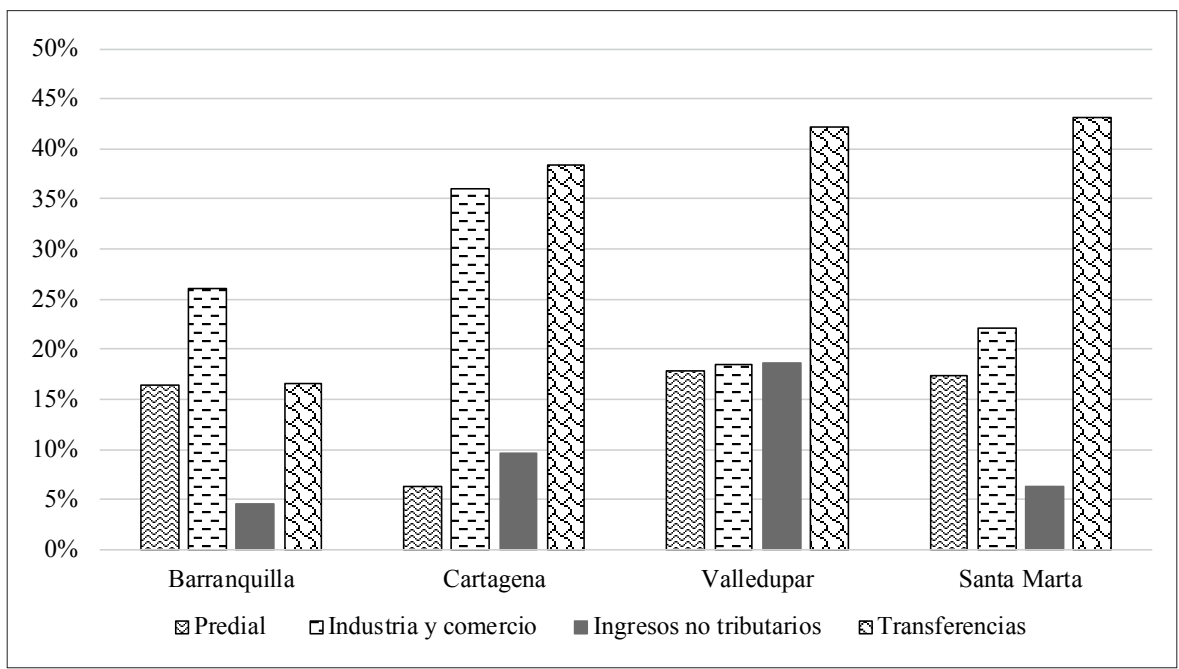

En cuanto a la participación ciudadana, uno de los programas destacados fue el de auto pavimentación de calles. En este esquema de ejecución de obras, cada familia beneficiada por la pavimentación de una vía debía aportar el cemento necesario para el frente de su vivienda y la mano de obra directa o contratada equivalente. En el caso de que algún vecino no se vinculara al financiamiento de la obra, se le descontaba por valorización el equivalente al frente de su residencia. Finalmente, y para la ejecución de las obras, el municipio suministraba las herramientas y los equipos necesarios para la construcción, iluminación, arborización y señalización final de las vías (Ochoa, 1998). De acuerdo con Rodolfo Campo Soto, en su primera y segunda administración se pavimentaron por autogestión comunitaria alrededor de 20 y 30 kilómetros de vías, respectivamente ${ }^{12}$.

Otro de los cambios en este periodo fue el aumento de la capacidad técnica del personal en la administración pública. Al respecto, Fiszbein (1997) señala que el número de profesionales pasó de 29 en 1988 a 118 en 1994. Por su parte, la proporción de empleados a profesionales bajó de 12,2 a 4,8. Este último indicador similar al encontrado en Chile, un caso comúnmente citado como ejemplo en fortalecimiento municipal (Campbell, Peterson, \& Brakarz, 1991).

Un último frente de trabajo estuvo constituido por la planificación, o como menciona el exalcalde Rodolfo Campo: "la planificación como norma de gobierno". De esta área hicieron parte el Plan de Desarrollo de Valledupar Siglo XXI (PDVS) y otros planes de más corto plazo, como el Plan de Acción
Gráfica 4.

Participación fuentes de ingreso Valledupar, Cartagena, Barranquilla y Santa Marta (1990)

Fuente: ejecuciones presupuestales DNP y cálculos de los autores. 
1994-1996. El primero fue formulado en el marco de la ley 9 de 1989 o ley de reforma urbana, la cual estableció que todos los municipios con una población mayor 100.000 habitantes debían formular su respectivo plan de desarrollo. Siguiendo esta reglamentación, en 1989 Valledupar presentó su nuevo plan, el cual fue elaborado por los mismos expertos planificadores del PIDUV liderados por la arquitecta Aurora Pachón (García, 1999).

En cuanto al crecimiento físico de la ciudad, el PDVS estableció que este debía promoverse en dirección sureste, específicamente hacia terrenos que pudiesen incorporarse fácilmente al perímetro de servicios y mantuviesen el desarrollo compacto de la ciudad. El PDVS promovió la conservación y consolidación del espacio público en la ciudad a través de planes más específicos, como el plan vial, el plan centro y el plan de arborización, entre otros. Además, presentó una propuesta para la relocalización de comunidades ubicadas en zonas de riesgo principalmente en los márgenes del río Guatapurí. Estas y otras consideraciones fueron aprobadas por el Concejo Municipal por medio del acuerdo 17 y 18 de 1990 (Asesorías Municipales, 1990).

La ejecución de las propuestas presentadas en el PDVS y sus planes complementarios, inició bajo la administración de Rodolfo Campo y continuó en la administración de Aníbal Martínez Zuleta, alcalde elegido para el periodo 1990-1992. A pesar de que este último contaba con una afiliación política distinta a la del primer alcalde, trabajó igualmente en la ejecución de los proyectos diseñados como parte del PDVS. Entre otros, ejecutó la obra de renovación del mercado viejo, basándose en el diseño de Carlos García y tomando el lote que había sido destinado para este propósito por la administración anterior. Además, continuó con la construcción de canales para la optimización completa del alcantarillado pluvial en la ciudad. ${ }^{13}$ Posteriormente, durante la segunda administración de Rodolfo Campo Soto (1993-1994), además de culminarse e inaugurarse el proyecto de la galería, se realizaron nuevos esfuerzos en materia de planeación. En particular, a través de la adopción del método de planificación estratégica situacional (PES) fundado por el economista chileno Carlos Matus. La PES consistía en tomar decisiones por adelantado, eligiendo estratégicamente el mejor camino para solucionar cada problema de la ciudad. Este comprendía la elaboración de programas de acción que establecieran prioridades en la asignación de recursos y tuvieran en cuenta las oportunidades y amenazas que se presentaban en el entorno (Huertas, 1993). 
Los esfuerzos en materia de planeación materializados con el PDVS permitieron dar continuidad al crecimiento ordenado de la ciudad. Según el DANE, en 1993, el déficit cualitativo de vivienda en Valledupar era el segundo más bajo de las capitales del Caribe y en la dimensión de acceso a servicios públicos la capital cesarense mostraba el mejor desempeño en la región. De acuerdo con Ochoa (1998), a finales de la década de los noventas, Valledupar contaba con tratamiento completo de sus aguas y 24 horas de servicio a presión. Adicionalmente, para la misma época, la administración estaba poniendo en práctica un nuevo plan maestro de acueducto y alcantarillado, el cual aspiraba a alcanzar un $97 \%$ de cobertura de alcantarillado y mantener las altas coberturas de acueducto.

La figura 3 presenta el crecimiento de la huella urbana a finales de los ochenta y primera mitad de los noventas. Como se puede observar, el crecimiento de la ciudad continuaba siendo relativamente compacto. Se terminan de consolidar en los ochentas los primeros barrios de invasión cerca del

Figura 3.

Crecimiento huella urbana Valledupar por barrios, 1993 río Guatapurí en una zona de importante riesgo de inundación. Algunos de estos barrios son el Once de Noviembre, el Pescadito y la Esperanza Oriente. También se observan nuevos desarrollos hacía el noroccidente con barrios como 5 de enero y 20 de julio. En el suroriente, por su parte, aparecen los barrios Candelaria Sur y Villa del Rosario (IDOM, 2015).

\section{Ley de Desarrollo Territorial y Plan de Ordenamiento Territorial 2000-2007}

El artículo 9 de la ley 388 de 1998 estableció que los distritos y municipios con población superior a 100.000 habitantes debían elaborar y adoptar su respectivo plan de ordenamiento territorial, en el cual se definieran las directrices para orientar y administrar el desarrollo físico del territorio y la utilización del suelo. En el marco de esta ley se elaboró el Plan de Ordenamiento Te-

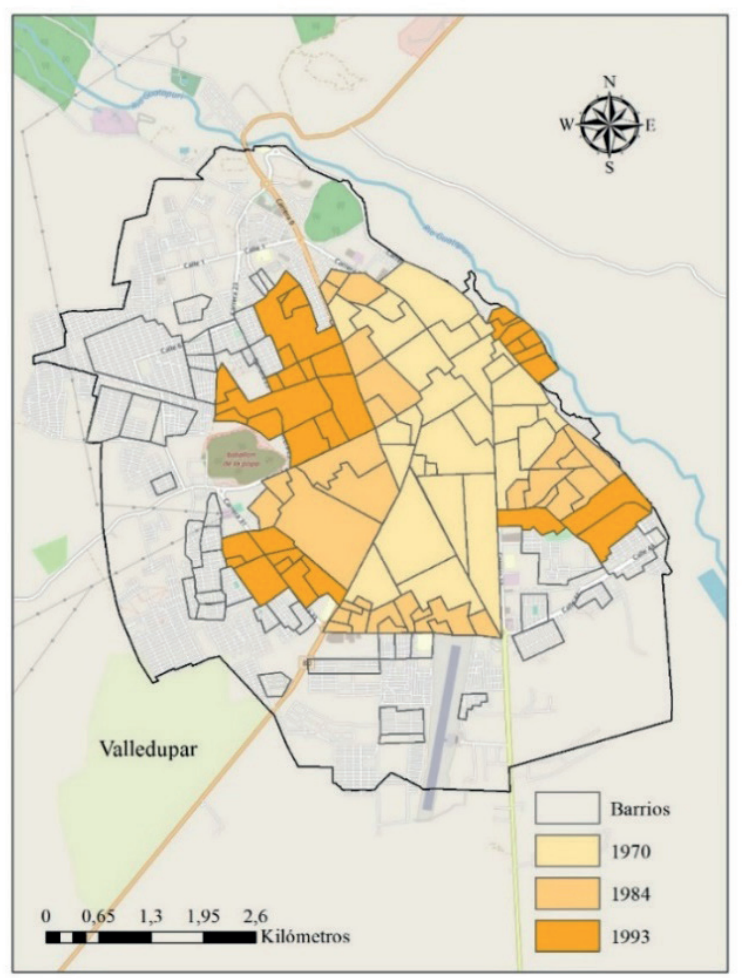
rritorial (POT) de Valledupar de 1999. Este último fue revisado mediante el Acuerdo 021 del 16 de Fuente: autores a partir de

cartografía de la Oficina Asesora diciembre de 2011 y actualizado en el marco del Acuerdo 011 de junio 5 de 2015 (IDOM, 2015).

de Planeación de Valedupar IDOM (2015) y cartografía histórica IGAC. 
A pesar de que la ley de desarrollo territorial fue la primera en incluir directrices específicas sobre el crecimiento físico del territorio y la utilización del suelo, este era un tema que Valledupar ya había abordado en sus planes anteriores y que, por lo tanto, conocía a cabalidad. Al igual que los planes anteriores, la elaboración del POT contó con la participación de la arquitecta Aurora Pachón, permitiendo dar continuidad a las propuestas sobre el ordenamiento de la ciudad. La secretaria de planeación de la administración 1998-2000, Sonia Gómez Taboada, señaló que:

"estando en el cargo debía elaborar el POT siguiendo lo establecido en la Ley 388 de 1998. Se encontró con toda la información que tenía la ciudad y conoció que la arquitecta Aurora Pachón había sido la asesora principal en la materia. La contactó para que continuara con ese trabajo y apoyara en la elaboración del POT, el cual fue fácil de elaborar por la tradición existente en planificación".14

EI POT abarcó, además de los temas usuales asociados al desarrollo físico de la ciudad y los usos de suelo, unas líneas de análisis que reflejaban problemáticas particulares de finales de la década de los noventa como: el alto crecimiento de la población debido entre otros a la llegada de desplazados, el elevado índice de desempleo y la precaria conservación del medio natural (Alcaldía de Valledupar, 1999).

En su conjunto, el POT y todos los planes que le antecedieron, permitieron a Valledupar mantener una trayectoria continua de desarrollo territorial ordenado. De acuerdo con los censos de población del DANE, Valledupar fue la ciudad que más avanzó en la reducción del déficit cuantitativo de vivienda en la región Caribe en el periodo 1993-2005. Este indicador pasó de 20 a $9 \%$, alcanzando el mejor desempeño en toda la región (gráfica 5). De manera similar, el déficit cualitativo de vivienda se redujo de 37 a $25 \%$, ubicándose como el tercero más bajo en la región después de Barranquilla y Cartagena (gráfica 6).

El buen desempeño, reflejado por estos indicadores, llevó a la ciudad a alcanzar un importante reconocimiento en Colombia y Latinoamérica. En 1998, el BID destacó el caso de Valledupar como una experiencia exitosa en gestión del desarrollo urbano en América Latina (Rojas \& Daughters, 1998). Además, de acuerdo con Angell et al. (2001), la capital cesarense fue considerada como una de las ciudades intermedias mejor planificadas de Colombia en el año 2000.

14 Entrevista con Sonia Gómez Taboada, 24 de enero de 2019. 

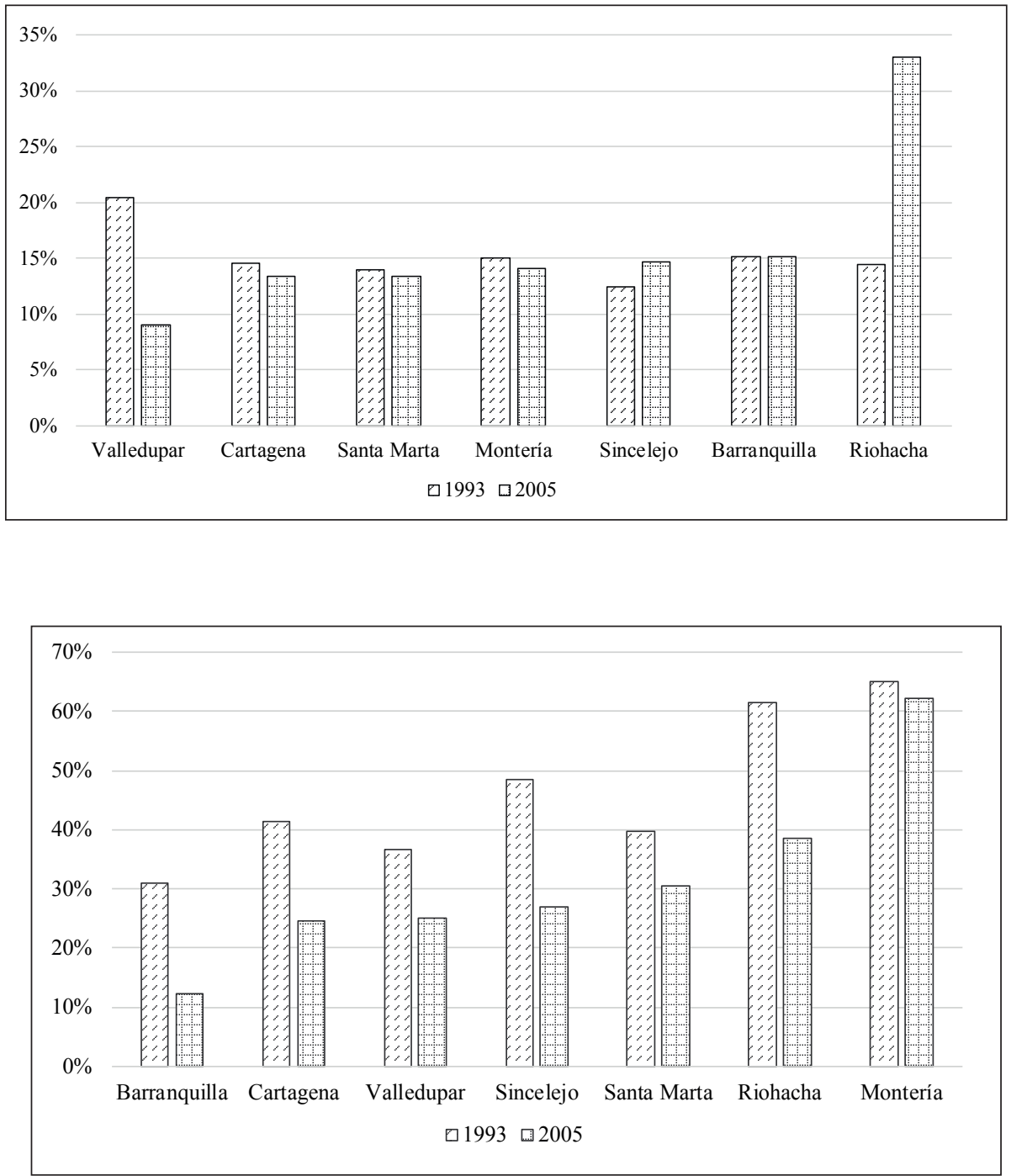

\section{RETOS DEL SIGLO XXI}

En los primeros años del presente siglo, el desplazamiento forzoso en Colombia se convirtió en una de las consecuencias más dramáticas de la violencia en el país (Centro Nacional de Memoria Histórica, 2013). De acuerdo con Ibañez y Moya, el desplazamiento aumentó desde mediados de la década de los noventa y alcanzó un número máximo de víctimas en el año 2002. Este fenómeno afectó a cerca del $90 \%$ de los municipios del país, tanto por recepción como por expulsión de personas. Sin embargo, su intensidad se vio concentrada en unos pocos municipios (Ibañez \& Moya, 2007).

En la región Caribe, una de las zonas más afectadas fue el corredor que une la Sierra Nevada de Santa Marta (Magdalena) con la Serranía del Perijá (Cesar), un lugar estratégico para el tránsito de armas y paso de ejércitos (DNP, 2014). De acuerdo con el Registro Único de Víctimas, Valledupar, una
Gráfica 5.

Déficit cuantitativo de vivienda, 1993 y 2005

Fuente: Censo Nacional de Población y Vivienda 1993 (DANE).

\section{Gráfica 6.}

Déficit cualitativo de vivienda, 1993 y 2005

Fuente: censo nacional de población y vivienda 1993 y 2005 (DANE). 
de las ciudades ubicadas en esta zona, conforma el grupo de las siete capitales con mayor recepción de personas desplazadas como porcentaje de su población en 2005.

Una gran parte de la población víctima del desplazamiento en la zona se concentró en la cabecera municipal de Valledupar. De acuerdo con el censo poblacional de 2005, la capital del Cesar era la segunda capital de la región Caribe con mayor número de inmigrantes (como porcentaje de su población) durante el periodo 2000-2005. Adicionalmente, según esta misma fuente de información, esta población se concentró en el extremo norte y sur occidental de la cabecera municipal (figura 4).

Los nuevos asentamientos en la periferia resultaron en la reconfiguración de la estructura urbana de la ciudad, que hasta la década de los noventa mantenía su forma relativamente compacta. Según IDOM (2015), y como se observa en la figura 5, en 2006 se hace evidente la presencia

Figura 4. de un crecimiento disperso con la aparición de barrios completamente Porcentaje de inmigrantes por sección urbana en Valledupar (2005) desarticulados de la ciudad. En particular, y en concordancia con la localización de la población inmigrante de principios de siglo, el desarrollo

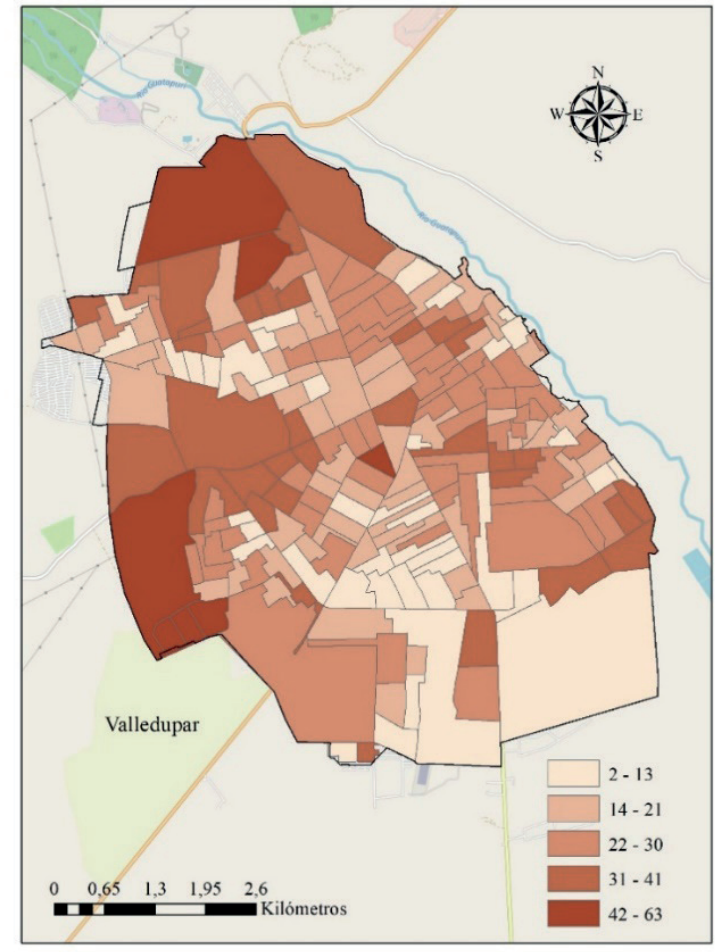

Fuente: autores a partir de información del Censo nacional de población y vivienda 2005 y cartografía (DANE). de mayor importancia se dio al occidente de la ciudad con barrios como el Divino Niño y La Nevada (IDOM, 2015).

En la actualidad, Valledupar sigue enfrentando dificultades para atender las demandas en bienes y servicios de grupos poblacionales que se establecen en la ciudad. Recientemente, se ha presentado el caso de la llegada masiva de venezolanos. De acuerdo con Otero, Herrera y Monroy (2019), este grupo poblacional creció de manera importante en el periodo 2012-2017, pasando de 0,7 por cada 1.000 habitantes a 10,9. El Registro Administrativo de Migrantes Venezolanos indica además que de los 19.978 venezolanos que eligen al Cesar como destino, $56 \%$ se concentra en Valledupar (Otero et al., 2019).

De acuerdo con Findeter (2017), debido a la falta de control y respuesta a todo este crecimiento por parte de la administración local, la ciudad ha ido buscando los espacios para suplir las necesidades de vivienda. Los desplazados 
y la población más vulnerable se han asentado en barrios ilegales y de invasión, sin ningún tipo de infraestructura para la provisión de servicios públicos, desarticulados de la ciudad y en algunos casos ubicados en zonas de alto riesgo.

\section{REFLEXIONES FINALES}

Figura 5.

Crecimiento huella urbana Valledupar por barrios, 2006

La revisión histórica del ordenamiento urbano de Valledupar deja lecciones para los procesos de planificación en ciudades intermedias de países en desarrollo. Un primer aspecto es la importancia de la visión de largo plazo en el diseño e implementación de las estrategias de desarrollo. La capital del Cesar enfrentó el crecimiento poblacional de mediados del siglo XX con la planificación del suelo y la ejecución de los proyectos de infraestructura urbana requeridos para atender adecuadamente la mayor demanda de suelo urbanizable. Un segundo elemento fue el fortalecimiento de la gestión fiscal, el cual ayudó a consolidar unas finanzas públicas sólidas para financiar y ejecutar las obras demandadas por la mayor población. Por su parte, la capacidad institucional local fue clave, reflejándose en una mejora en la razón de empleados a profesionales en la administración pública durante la década

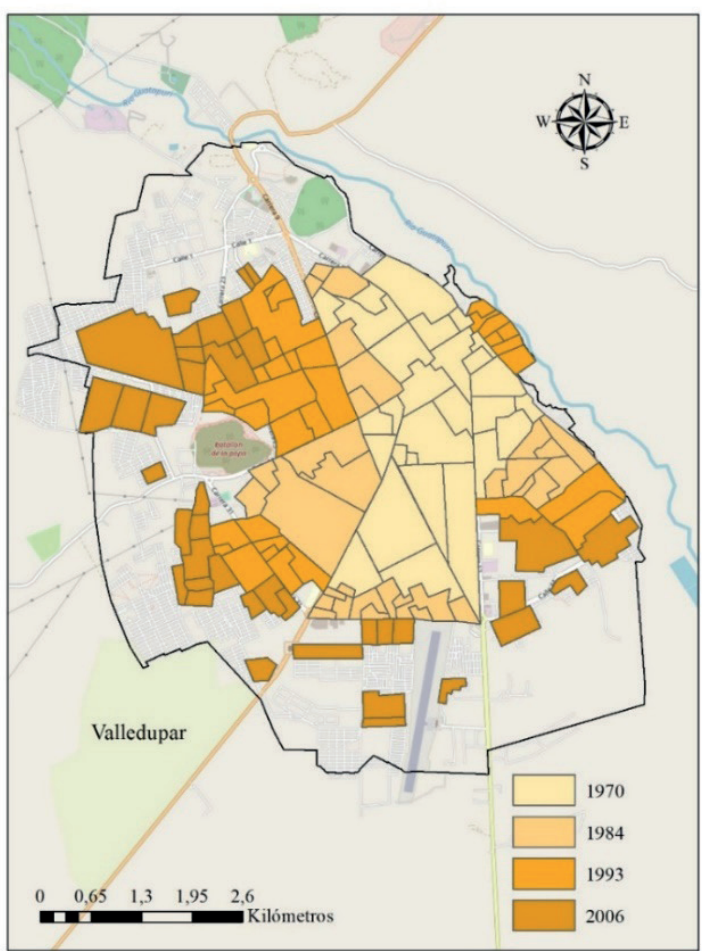

Fuente: Elaboración de los autores a partir de cartografía de la Oficina Asesora de Planeación de Valedupar, IDOM (2015) y cartografía histórica IGAC. ejemplo nacional durante ese periodo. Vale la pena también destacar la participación ciudadana a través de los programas de auto gestión comunitaria, lo cual permitió realizar con éxito la pavimentación de distintos barrios en la ciudad.

Un último elemento destacable fue la continuidad en el proceso de planificación a través de las distintas administraciones públicas. Sin importar el partido político que estaba en el poder, las directrices en materia de desarrollo y ordenamiento urbano se mantenían y se respetaban. Un reflejo de esto es el hecho de que la arquitecta Aurora Pachón se mantuvo como asesora del municipio entre 1982 y 2002, con alcaldes designados y por elección popular de distintas afiliaciones políticas. Algo muy particular del 
ordenamiento urbano de Valledupar y que permitió que en su momento se le reconociera como la ciudad "Sorpresa Caribe". ${ }^{15}$

En el transcurso del siglo XXI, Valledupar ha tenido que enfrentar nuevos retos asociados al ordenamiento de su territorio. De acuerdo con el Registro Único de Víctimas, Valledupar conforma el grupo de las siete capitales del país con mayor recepción de personas desplazadas como porcentaje de su población en 2005. Además, en años recientes la capital del Cesar ha experimentado la llegada de migrantes venezolanos (Otero et al., 2019). Esta situación impone desafíos a la política pública y en especial al ordenamiento urbano de la ciudad. Existe un POT aprobado hace un par de años y varios estudios recientes que entregan recomendaciones sobre la planeación urbana del municipio. Retomar la tendencia de planeación de largo plazo con instituciones sólidas es uno de los retos que debe orientar las acciones de política pública vallenata en los próximos años.

\section{REFERENCIAS}

Alcaldía de Valledupar. (1999). Plan de Ordenamiento Territorial- Componente Urbano. Valledupar: Alcaldía de Valledupar.

Angell, A., Lowden, P., \& Thorp, R. (2001). Descentralizing Development: The political economy of institutional change in Colombia and Chile. Oxford University Press.

Asesorías Municipales. (1990). Plan de Desarrollo Valledupar Siglo XXI. Valledupar: Alcaldía de Valledupar.

Bell, C. (2016). Ruta Carrerá. Barranquilla: El Heraldo.

Beuf, A. (2012). Concepción de centralidades urbanas y planeación del crecimiento urbano en la Bogotá del siglo XX. En XII Coloquio Internacional de Geocrítica. Bogotá, mayo 7-11.

Bonet, J., Pérez, G., \& Ricciulli, D. (2018). ¿Hay pereza fiscal territorial en Colombia? Revista de Economía del Rosario, 21(2), 247-307. https://doi. org/10.12804/revistas.urosario.edu.co/economia/a.7196

Cabeza, A. (2004). Ordenamiento territorial: experiencias internacionales y desarrollos conceptuales y legales realizados en Colombia. Revista Perspectiva Geográfica, 4, 7-75.

Campbell, T., Peterson, G., \& Brakarz, J. (1991). Decentralization to Local Government in LAC: National Strategies and Local Response in Planning,

15 Periódico El Pilón, 6 de octubre de 2014. 
Spending and Management. Latin America and the Caribbean Technical Department Regional Studies Program.

Centro Nacional de Memoria Histórica. (2013). BASTA YA Colombia: Memorias de guerra y dignidad. Bogotá: Departamento para la Prosperidad Social.

Castrillón, A., \& Cardona, S. (2014) El urbanismo y la planeación moderna. Glocalidades en la formación de la modernidad urbana de Medellín. Historia y Sociedad, 26, 17-51. https://doi.org/10.15446/hys. $\mathrm{n} 26.44383$

Cuello, M. G. (2015). Mis Recuerdos 1915-2003 Conversaciones con Jaime Calderón Brugés. Valledupar.

Dangond, J. (2002). Renacimiento de Valledupar. Barranquilla: Casa Editorial Antillas.

Empresa de Obras Sanitarias de Valledupar [Empodupar]. (1984). Informe de Actividades 1984. Valledupar: Ministerio de Salud Pública/Insfopal.

Empresa de Servicios Públicos de Valledupar [Emdupar]. (2018). Estados FInancieros Consolidados a diciembre de 2018. Valledupar: Emdupar.

Fernández, L. G. (2011). Crecimiento urbano y cambio social en Valledupar 1950-2000. Valledupar: Universidad Popular del Cesar.

Financiera del Desarrollo [Findeter]. (2017). Planeando Ciudades Sostenibles Crecimiento urbano, gestión del riesgo y cambio climático. Bogotá: Findeter.

Fiszbein, A. (1997). The Emergence of Local Capacity: Lessons from Colombia. World Development, 25(7), 1029-1043. https://doi.org/10.1016/ S0305-750X(97)00020-X

García, C. (1999). Valledupar, ciudad entre ciudades. Cuadernos Regionales, 6, 455-480.

García, C. (s.f.). De aldea a ciudad. Manuscrito sin publicar.

Huertas, F. (1993). El método PES Planeación Estratégica Situacional. Entrevista a Carlos Matus. Ecuador: CEREB.

Ibañez, A., \& Moya, A. (2007). La población desplazada en Colombia: Examen de sus condiciones socioeconómicas y análisis de las políticas actuales. Bogotá: DNP. 
IDOM. (2015). Estudios base municipio de Valledupar. Programa de ciudades sostenibles y competitivas. Módulo 3: Estudio de crecimiento urbano. Bogotá: Findeter.

Instituto Geográfico Agustín Codazzi [IGAC]. (1969). Plan Piloto de Desarrollo Urbano de Valledupar 1969. Valledupar: IGAC.

Instituto Nacional de Fomento Municipal [Insfopal]. (1961). Acueducto de Valledupar Proyecto de Plan de Tratamiento de Aguas Potables. Valledupar: Lobo Guerrero \& C.S. De Santamaría Ltda.

Levy, J. (2017). Contemporary Urban Planning. New York: Routledge. https:// doi.org/10.4324/9781315619408

Maldonado, A. (2004). Tax Mangement in the Municipalities of Valledupar and Manizales, Colombia. En W. Bank, T. Campbell, \& H. Fuhr (eds.). Leadership and Innovation in Subnational Government (pp. 99-121). Washington, DC: WBI Development Studies.

Ochoa, E. (1998). La gestión municipal en Valledupar. En E. Rojas \& R. Daughters (eds.). La ciudad en el siglo XXI: experiencias exitosas en gestión. Washington, D.C.: Banco Interamericano de Desarrollo.

Otero, A., Herrera, F., \& Monroy, J. (2019). Análisis de la pobreza y condiciones de vida en Valledupar. Bogotá: Banco de la República.

Pachón, A. (1983). Plan Integral de Desarrollo de Valledupar. Bogotá: FONADE.

Programa Expansión Urbana NYU. (2016). Proyecto: Iniciativa de Expansión Urbana en Colombia - Resumen Ejecutivo. Bogotá: CAF.

Richert, E., \& Lapping, M. (1998). Ebenezer Howard and the Garden City. Journal of the American Planning Association, 64(2), 125-127. https:// doi.org/10.1080/01944369808975966

Rojas, E., \& Daughters, R. (eds.). (1998). La ciudad en el siglo XXI: experiencias exitosas en gestión del desarrollo urbano en América Latina. Washington, D.C.: Banco Interamericano de Desarrollo.

Salazar, J. (2007). La planeación de Bogotá: un sistema híbrido de desarrollo progresivo. Revista Bitácora Urbano Territorial, 11(1), 208-219.

Vélez, L. (2013). Evolución de las empresas de agua y saneamiento de Medellín y Cali en Colombia: ¿vidas paralelas? Nota Técnica. Banco Interamericano de Desarrollo Sector de Infraestructura y Medio Ambiente. 


\section{Archivos históricos y entrevistas}

Entrevista con Heriberto Mendoza, Valledupar, 4 de diciembre de 2018.

Entrevista con María Clara Quintero, Valledupar, 4 de diciembre de 2018.

Entrevista con Rodolfo Campo Soto, Valledupar, 4 de diciembre de 2018.

Entrevista con Sonia Gómez Taboada, Bogotá, 24 de enero de 2019.

Entrevista con Aurora Pachón, vía telefónica, 24 de enero de 2019.

Entrevista con Carlos García Aragón, 5 de diciembre de 2018.

Entrevista con Augusto Ramírez Uhía, 28 de febrero de 2019.

\section{Prensa}

Periódico Antena del Cesar, 21 de diciembre de 1975.

Periódico Antena del Cesar, 10 de marzo de 1975.

El Diario Vallenato, 7 de septiembre de 1987.

El Diario Vallenato, 1 de agosto de 1987.

El Diario Vallenato, 30 de julio de 1987.

El Diario Vallenato, 6 de agosto de 1987.

El Diario Vallenato, 25 de septiembre de 1987.

El Diario Vallenato, 18 de septiembre de 1989.

El Tiempo, 9 de febrero de 1994. 